\title{
Profiles of Children with Lower Extremity Fracture at Saiful Anwar Malang Regional General Hospital from January 2016 to August 2020
}

\author{
Panji Sananta*(i), Rizky Julana(D), Muhammad Alwy Sugiarto(i) \\ Department of Orthopaedic and Traumatology, Faculty of Medicine, Universitas Brawijaya, Saiful Anwar General Hospital, \\ Malang, Indonesia
}

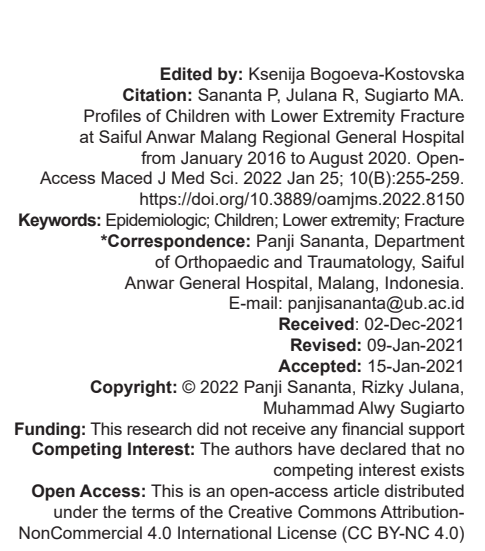

Introduction

Musculoskeletal injuries in children are common, causing $25 \%$ of children's hospitalization. One of the prevalent injuries is a traumatic fracture [1]. It serves as the main source of morbidity, disability, socioeconomic burden, and mortality. Approximately 10 million children are treated for injuries every year, and more than 9000 children die in the United States due to trauma [2]. Childhood injuries are common. The previous research stated that approximately $25 \%$ of children had a trauma injury annually, and five pediatric fractures had significant long-term consequences such as activity restriction [3]. Landin was a leader in a pediatric population based on fracture epidemiology. He reported age- and sex-related fracture patterns in 8682 cases from Malmö, Sweden, during 30 years. The most common fracture found was distal forearm fracture [4], [5].

On the other hand, the previous research conducted by Chaibi et al. and Liu et al. focused on the epidemiology of lower extremity fractures in children. From their studies, the most common fracture site was tibial [6], [7]. About $20 \%$ of all fractures that happened in children were in lower extremities [6]. In Indonesia, there have been epidemiology studies that discussed the incidence of fracture in general sites, but there are not many that reported lower limb fractures [8], [9]. Because of scarce studies, the authors decided to perform this study to further learn about gender, age, mechanism of injury, and treatment characteristics of pediatric patients with lower extremity fractures at a tertiary hospital. Children and adults had significantly different fractures features. Therefore, their management was different [1].

With these results, the authors expect this research to be used for lower extremities fractures in children's epidemiologic descriptions, especially in a developing country like Indonesia. It can also be used as a reference to improve management (planning, implementation, monitoring, and assessment) and health services in the lower extremity fracture.

\section{Methods}

The Ethical Committee of the Medical Research Faculty of Universitas Brawijaya had approved all 
protocols. All subsequent experiments were carried out according to the relevant guidelines and regulations.

We performed a retrospective cross-sectional study based on all pediatric trauma injuries registered to the RSUD Dr. Syaiful Anwar, a tertiary referral hospital in Indonesia, emergency room.

\section{Study population}

Between January 2016 and September 2020, we included 774 children (0-18 years old) admitted to our hospitals with traumatic fractures at any location and caused by any mechanism of injury.

Inclusion criteria were children under 18 years old with lower limb fractures due to all kinds of trauma mechanisms, such as falling from $1 \mathrm{~m}$ or less altitude, traffic accidents, being penetrated by sharp objects, and others from January 2016 to September 2020. Exclusion criteria were fractures at other locations besides the lower limb, such as an upper limb, spine, pelvis, and any laceration/soft-tissue injuries. Children who presented with any specific pathologic process that affects bone and mineral metabolism and refused an orthopedic screening were also excluded from the study. The epidemiology data were obtained from the hospital medical records. We established a definitive diagnosis of the lower limb traumatic fracture using X-rays and computed tomography scans in all fracture causes.

Age, gender, mechanism of injury, type of fracture, and treatment data were recorded. We use the $A O$ classification system to classify femoral and leg fractures [6]. Fractures treatment included splint/ bracing, closed reduction with a cast, CRPP, ORIF, plating, and others.

\section{Statistical analysis}

All statistical analyses were performed using SPSS version 26.0. We used Pearson Chi-square tests to assess the frequency differences and independent samples t-tests to assess continuous variables differences.

\section{Results}

From 774 pediatric patients who presented with traumatic injury, we excluded 527 patients who did not meet the inclusion criteria. Therefore, we analyzed 247 children in this study. There were 169 (68.4\%) boys and 78 (31.6\%) girls with a lower limb fracture. The mean age was 13 years and 9 months (ranging from 1 month to 18 years). The patients' age distribution from Figure 1 in order was age $<3$ years $2 \%$, age $3-6$ years $12.6 \%$, age $7-12$ years $19 \%$, and $13-18$ years old accounted $66.4 \%$ which is incidence peaked in both male and female patients.

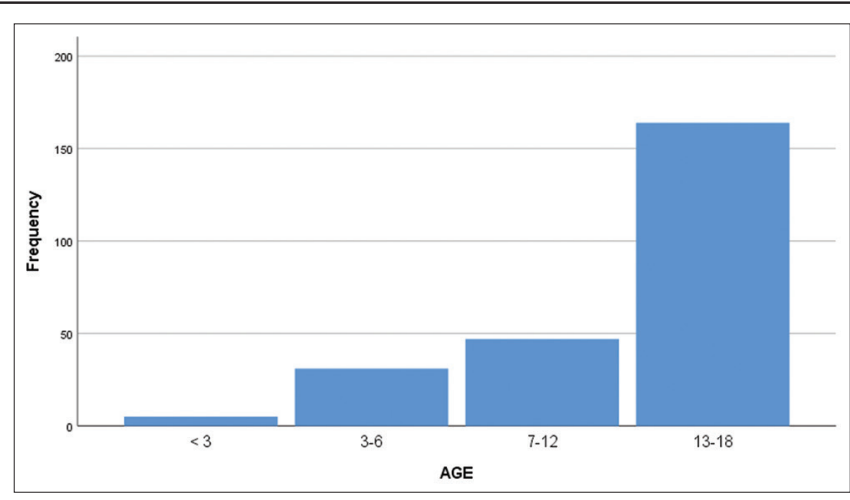

Figure 1: Age study population

According to Table 1, the most common etiology was traffic accidents (motor vehicle accidents), 210 patients $(85 \%)$, followed by falling from a height of more than $1 \mathrm{~m}, 15$ patients $(6.1 \%)$, struck by a sharp object, falling from a height $<1 \mathrm{~m}$, and other causes, 6 patients $(2.4 \%)$ each. The least cause was sportrelated injury, accounted for 4 patients (1.6\%).

Table 1: Overview of epidemiology studies of fractures in children

\begin{tabular}{lllll}
\hline First author & Age group & Study period & Most common fracture & Location \\
\hline Landin & $0-16$ & $1950-1979$ & Distal forearm $(23 \%)$ & Sweden \\
Liu & $0-18$ & $2001-2010$ & Tibia $(40.2 \%)$ & China \\
Chaibi & $0-16$ & $2017-2018$ & Tibia $(38 \%)$ & Switzerland \\
Wijaya & $12-18$ & $2016-2017$ & Radius-ulna $(12.7 \%)$ & Indonesia \\
Sananta & $0-18$ & $2016-2020$ & Radius-ulna $(21.2 \%)$ & Indonesia \\
\hline
\end{tabular}

Researchers looked for the relationship between the mechanism of injury with age and fracture location. The results showed $p=0.006$ and 0.040 , respectively. Both $p<0.05$ indicated a statistically significant relationship between the mechanism of injury with age and fracture location.

Table 2 shows that the most age group with fractures due to fell from a height $<1 \mathrm{~m}$ was ages 3-6 years old, with 3 children $(50 \%)$, followed by ages $7-12$ years old, 2 children $(33.3 \%)$, and ages 13-18 years old, 1 child (16.7\%). For fractures due to fell from a height of more than $1 \mathrm{~m}, 9$ children $(60 \%)$ aged 13-18 years old, 3 children (20\%) aged 3-6 years old, and another 3 children (20\%) aged $7-12$ years old.

Motor vehicle accidents were held responsible for $85 \%$ of all fractures in children (Figure 2). These events were dominant in the 13-18 years old group, reported as many as 145 children (69\%). This number was followed by the 7-12-yearold group, 41 children (19.5\%) and the under 7-year-old group, 20 children (9.5\%). Furthermore, being struck by a sharp object mostly occurred in children aged 3-6 years old (50\%) followed by the age of 13-18 years old (33.3\%). All sport-related injuries happened only in children ages 13-18 years old. Other fracture causes accounted for 3 children (50\%) aged 13-18 years old.

Meanwhile, falls from a height of $1 \mathrm{~m}$ causes three children (50\%) suffering femur fractures, two children $(33.3 \%)$ suffering tibia/fibula fractures, and one child $(16.7 \%)$ suffering a foot/ankle fracture. Then, in cases of falling from a height of more than $1 \mathrm{~m}$, femur fractures occurred in 8 children (53\%), tibia/fibula 
Table 2: Etiology of patients with traumatic lower limb fractures

\begin{tabular}{|c|c|c|c|c|c|c|c|c|}
\hline Etiology & Fall $<1 \mathrm{~m}$ & Fall $>1 \mathrm{~m}$ & MVA & Struck by a sharp object & Sport-related injury & Others & Total & Sig \\
\hline Total & $6(2.4)$ & $15(6.1)$ & $210(85.0)$ & $6(2.4)$ & $4(1.6)$ & $6(2.4)$ & $247(100)$ & \\
\hline \multicolumn{4}{|l|}{ Age } & $4 / 2(2.0)$ & $3 / 1(3.0)$ & $4 / 2(2.0)$ & $169 / 78(2.17)$ & 0.944 \\
\hline$<3$ & $0(0)$ & $0(0)$ & $4(1.9)$ & $0(0)$ & $0(0)$ & $1(16.7)$ & $5(2.0)$ & \multirow[t]{5}{*}{0.006} \\
\hline $3-6$ & $3(50.0)$ & $3(20.0)$ & $20(9.5)$ & $3(50.0)$ & $0(0)$ & $2(33.3)$ & 31 (12.6) & \\
\hline $7-12$ & $2(33.3)$ & $3(20.0)$ & 41 (19.5) & $1(16.7)$ & $0(0)$ & $0(0)$ & $47(19.0)$ & \\
\hline $13-18$ & $1(16.7)$ & $9(60.0)$ & $145(69.0)$ & $2(33.3)$ & $4(100)$ & $3(50.0)$ & $164(66.4)$ & \\
\hline Total & $6(100)$ & $15(100)$ & $210(100)$ & $6(100)$ & $4(100)$ & $6(100)$ & $247(100)$ & \\
\hline \multicolumn{9}{|l|}{ Fracture sites } \\
\hline Femur & $3(50.0)$ & $8(53.3)$ & $113(53.8)$ & $1(16.7)$ & $1(25.0)$ & $4(66.7)$ & $130(52.6)$ & \multirow[t]{4}{*}{0.040} \\
\hline Tibia/fibula & $2(33.3)$ & $4(26.7)$ & $60(28.6)$ & $0(0)$ & $1(25.0)$ & $1(16.7)$ & 68 (27.5) & \\
\hline Foot/ankle & $1(16.7)$ & $3(20.0)$ & 37 (17.6) & $5(83.3)$ & $2(50.0)$ & $1(16.7)$ & 49 (19.8) & \\
\hline Total & $6(100)$ & $15(100)$ & $210(100)$ & $6(100)$ & $4(100)$ & $6(100)$ & $247(100)$ & \\
\hline
\end{tabular}

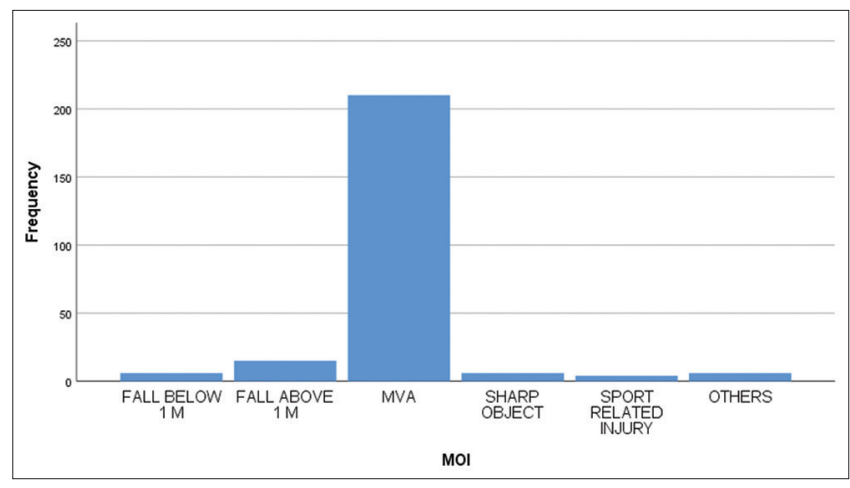

Figure 2: Mechanism of injury for lower extremity fracture

fractures in 4 children $(26.7 \%)$, and foot/ankle fractures in 3 children (17.6\%). Motor vehicle accident (MVA), which occurred in 210 children, resulted in $113(53.8 \%)$ femur fractures, $60(28.6 \%)$ tibia/fibula fractures, and $37(17.6 \%)$ foot/ankle fractures.

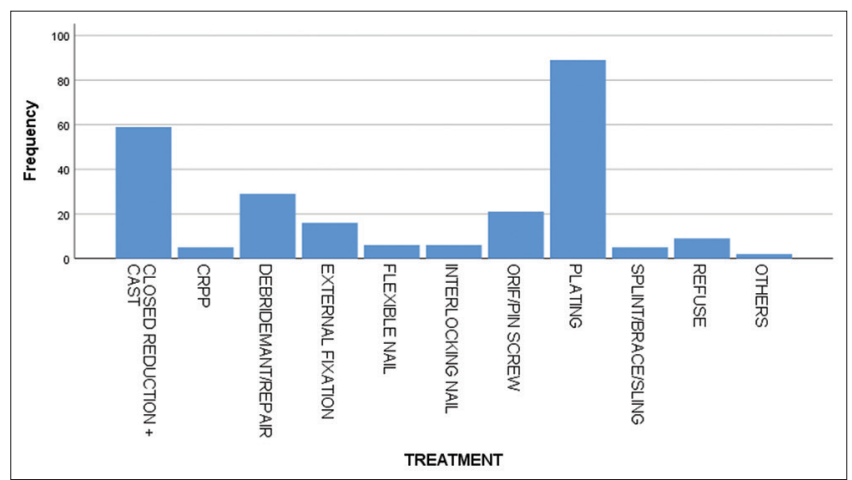

Figure 3: Treatment for fracture in lower limb. Almost $68 \%$ of all patients underwent plating surgery

In addition, based on Table 3 , the most common fractures in children under the age of 18 were femur accounted for 130 children (52.6\%). In the second place, tibia/fibula fractures accounted for 68 children

Table 3: Characteristics of traumatic fracture according to age groups

\begin{tabular}{lllllll}
\hline Age range & $<3$ & $3-6$ & $7-12$ & $13-18$ & Total & Sig \\
\hline Total & $5(2.0)$ & $31(12.6)$ & $47(19.0)$ & $164(66.4)$ & $247(100)$ & \\
$\begin{array}{l}\text { Male/female } \\
\text { Fracture site }\end{array}$ & $2 / 3(0.67)$ & $19 / 12(1.58)$ & $31 / 16(1.93)$ & $117 / 47(2.49)$ & $169 / 78(2.16)$ & 0.337 \\
$\quad$ Femur & $3(60.0)$ & $22(71.0)$ & $32(52.5)$ & $73(48.7)$ & $130(52.6)$ & 0.479 \\
$\quad$ Tibia/ & $0(0)$ & $6(19.4)$ & $20(32.8)$ & $42(28.0)$ & $68(27.5)$ & \\
$\quad$ fibula & & & & & & \\
$\quad \begin{array}{l}\text { Foot/ankle } \\
\text { Total }\end{array}$ & $5(40.0)$ & $3(9.7)$ & $9(14.8)$ & $35(23.3)$ & $49(19.8)$ & \\
\hline
\end{tabular}

(27.5\%), and finally, foot/ankle fractures accounted for 49 children (19.8\%). From these data, we described those children under 3 years old mostly had a femur fracture, 3 children $(60 \%)$, followed by a foot/ankle fracture, 2 children. Femur fractures were also known as the most common injury sites in children aged $3-6$ years old $(22$ children $-71 \%$ ) followed by tibia/fibula fractures $(19.4 \%)$ and foot/ankle fractures in 3 children $(9.7 \%)$. In the aged of 7-12 years old, femur fractures accounted as the most prevalent injuries in 32 children $(52.5 \%)$ followed by tibia fibula fractures in 20 children $(32.8 \%)$ and ankle/foot fractures in 9 children (14.8\%). Finally, in children aged $12-18$ years, femur fractures occurred in 130 children $(52.6 \%)$, tibia fibula fracture in 42 children $(27,5 \%)$, and foot-ankle fracture in 35 children (19.8\%).

Table 4: Choice of treatment based on the injury location

\begin{tabular}{llllll}
\hline Fracture side & Femur & Tibia/fibula & Ankle & Total & Sig. \\
\hline Total & 130 & 68 & 49 & 247 & 0.479 \\
$\begin{array}{l}\text { Male/female } \\
\text { Treatment }\end{array}$ & $91 / 39(2.3)$ & $48 / 20(2.4)$ & $30 / 19(1.5)$ & $169 / 78(2.2)$ & \\
$\quad$ Closed reduction & $26(20.0)$ & $28(42.2)$ & $5(10.2)$ & $59(23.9)$ & 0.000 \\
CRPP & $1(0.8)$ & $2(2.9)$ & $2(4.1)$ & $5(2.0)$ & \\
Debridement/repair & $5(3.8)$ & $4(5.9)$ & $20(40.8)$ & $29(11.7)$ & \\
External fixation & $8(6.2)$ & $8(11.8)$ & $0(0.0)$ & $16(6.5)$ & \\
Flexible nail & $6(4.6)$ & $0(0.0)$ & $0(0.0)$ & $6(2.4)$ & \\
Interlocking nail & $4(3.1)$ & $2(2.9)$ & $0(0.0)$ & $6(2.4)$ & \\
ORIF/pin screw & $6(4.6)$ & $1(1.5)$ & $14(28.6)$ & $21(8.5)$ & \\
Plating & $68(52.3)$ & $18(26.5)$ & $3(6.1)$ & $89(36.0)$ & \\
Splinting/brace/sling & $0(0.0)$ & $0(0)$ & $5(10.2)$ & $5(2.0)$ & \\
Refuse & $5(3.8)$ & $4(5.9)$ & $0(0.0)$ & $9(3.6)$ & \\
Others & $1(0.8)$ & $1(1.5)$ & $0(0.0)$ & $2(0.8)$ & \\
$\quad$ Total & $130(100)$ & $68(100)$ & $49(100)$ & $247(100)$ & \\
\hline
\end{tabular}

In femoral fractures (Table 4), the plating was generally used in 68 cases $(52.3 \%)$, closed reduction in 26 cases $(20 \%)$, external fixation in 8 cases $(6.2 \%)$, and flexible nailing in 6 cases (4.6\%). Then, in tibia/fibula fractures, closed reduction was performed in 28 cases $(42.2 \%)$, which was the common treatment choice. Plating and external fixation were used in 18 cases $(26.5 \%)$ and $8(6.2 \%)$, respectively. At last, for ankle fractures, the most frequent therapy was debridement/ repair in 20 cases (40.8\%), ORIF/pin screw in 14 cases $(28.6 \%)$, and closed reduction and splinting/bracing/ sling in 5 cases (10.2\%) each (Figure 3 ).

Table 5 presents that in the group of children under 3 years old, treatment which performed mostly was closed reduction 3 cases (60\%) and debridement/ repair 2 cases $(40 \%)$. Then, in children aged $3-6$ years old, closed reduction was done in 20 cases (64.5\%), the most widely used method followed by plating in five cases (16.1\%). In children aged 7-12 years old, the most widely used therapy was a closed reduction, 
Table 5: Choice of treatment based on age groups

\begin{tabular}{|c|c|c|c|c|c|c|}
\hline Age range & $<3$ & $3-6$ & $7-12$ & $13-18$ & Total & Sig. \\
\hline Total & $5(2.0)$ & 31 (12.6) & $47(19.0)$ & $164(66.4)$ & $247(100)$ & 0.337 \\
\hline Male/female & $2 / 3(0.67)$ & $19 / 12(1.58)$ & $31 / 16(1.93)$ & $117 / 47(2.49)$ & $169 / 78(2.16)$ & \\
\hline \multicolumn{7}{|l|}{ Treatment } \\
\hline Closed reduction & $3(60.0)$ & $20(64.5)$ & $18(38.3)$ & $18(11.0)$ & $59(23.9)$ & 0.000 \\
\hline CRPP & $0(0.0)$ & $2(6.5)$ & $2(4.3)$ & $1(0.6)$ & $5(2.0)$ & \\
\hline Debridement/repair & $2(40.0)$ & $2(6.5)$ & $6(12.8)$ & $19(11.6)$ & 29 11.7) & \\
\hline External fixation & $0(0.0)$ & $0(0.0)$ & $3(6.4)$ & $13(7.9)$ & $16(6.5)$ & \\
\hline Flexible nail & $0(0.0)$ & $1(3.2)$ & $5(10.6)$ & $0(0.0)$ & $6(2.4)$ & \\
\hline Interlocking nail & $0(0.0)$ & $0(0.0)$ & $1(2.1)$ & $5(3.0)$ & $6(2.4)$ & \\
\hline ORIF/pin screw & $0(0.0)$ & $1(3.2)$ & $3(6.4)$ & $17(10.4)$ & $21(8.5)$ & \\
\hline Plating & $0(0.0)$ & $5(16.1)$ & $7(14.9)$ & $77(47.0)$ & $89(36.0)$ & \\
\hline Splinting/brace/sling & $0(0.0)$ & $0(0.0)$ & $1(2.1)$ & $4(2.4)$ & $5(2.0)$ & \\
\hline Refuse & $0(0.0)$ & $0(0.0)$ & $1(2.1)$ & $8(4.9)$ & $9(3.6)$ & \\
\hline Others & $0(0.0)$ & $0(0.0)$ & $0(0.0)$ & $2(1.2)$ & $2(0.8)$ & \\
\hline Total & $5(100)$ & $31(100)$ & $47(100)$ & $164(100)$ & $247(100)$ & \\
\hline
\end{tabular}

performed in 18 cases (28.3\%), plating in 7 cases (14.9\%), and debridement/repair in 6 cases $(12.8 \%)$. For the 13-18-year-old group, ORIF/pin screw was the chosen therapeutic option in 77 cases $(47 \%)$, debridement in 19 cases (11.6\%), and closed reduction in 18 cases $(11.0 \%)$.

\section{Discussion}

Several studies explained the incidence of fractures in children. Some of them also described the lower limb fractures incidence in children. However, epidemiology trends, overall patterns, and treatment options have not been studied in Indonesia. This study evaluated fractures due to trauma in 247 children under 18 years old from 2016 to 2020 .

Based on gender, the previous studies showed that boys were more likely to sustain a fracture than girls [1], [5], in line with this study that resulted in twice incidence of fractures in boys than girls. Male predominance recorded in the most research related to more action and engagement in harmful physical activities than girls. These tendencies were observed in most countries, especially in Indonesia, China, and Swiss, usually in children aged 13-18 years old [10].

Motor vehicle accidents were the most common fracture causes, according to the previous researches. The most common causes were MVCs (47.0\%) followed by low falls (26.0\%) [7]. From this study, we found that 210 patients $(85 \%)$ fractured due to traffic accidents (MVA), with the highest percentage in 13-18 years old, followed by falling from a height of more than $1 \mathrm{~m}$ in 15 patients $(6.1 \%)$. The incidence of fractures caused by MVA increased with age. It had a significance value $<0.05$, so it can be concluded that motor vehicle accidents had a relationship with children's fractures. From some previous study confirmed this result, which stated that fractures in children occurred predominantly due to traffic accidents. The high incidence of femur fractures was most likely due to high-energy trauma, resulting in MVA mechanism as the most common type of injury [1]. Similarly, in a previous study, they discovered that the number of femur fractures increased with increasing age [3], [7], [10].

Choice of therapy is an important aspect of epidemiological research because it could describe the quality of health services and the optimal therapeutic option. In this study, the most common fractures were femoral fractures, which occurred in up to 130 cases and were mostly detected in children aged $13-18$ years. The most common treatment methods for femoral fractures were plating in 68 children (52.3\%) and closed reduction in 26 children (20\%). Plating was the preferred method. It was supported by a study conducted by Sutphen et al. in 2016 that stated submuscular plating led to decreased union time, increased complete weightbearing, and decreased risk of complications [11]. Then, the second most common lower limb fractures were tibia/fibula fractures. The treatment of choice for this fracture type was a closed reduction in 28 children $(42.2 \%)$ and plating in 6 children $(26.5 \%)$, considering closed reduction is the most common treatment in an uncomplicated tibial fracture. In general, closed reduction and cast immobilization were more effective than other treatments [12]. Surgical intervention was recommended for open, irreducible fractures that have failed a non-operative therapy, accompanied by compartment syndrome, or in the patient who had multiple injuries [13]. Finally, fractures that occurred in the ankle were the least type among the others. The chosen treatment was debridement/repair in 20 children (40.8\%) and ORIF in 14 children (28.6\%). Limb salvage and timely fracture union were possible in children with complex lower limb trauma. Early intervention with appropriate debridement, skeletal stabilization, and early soft-tissue coverage in children result satisfactory outcomes [14].

\section{Conclusion}

This study has shown that the incidence of lower limb fractures in children was similar as the age increased, with the most frequent cause was traffic accidents. It was held responsible for most 
femur fractures. Abandoning the fracture leads to the risk of disability and disrupting the child's future. The therapeutic options selected from this study can be taken into consideration for therapy options.

The limitation of this study included fractures of more than 1 site, which was different from other studies that ensured only examined a single fracture, such as isolated femur fracture or tibia fracture, this would be a fruitful area for further work. Ethnic and gene factors were not explored in this study, it also can be used as a basis for further epidemiological research.

\section{References}

1. Gogi N, Deriu L. Common paediatric lower limb injuries. Surg (Oxford). 2017;35(1):27-32. https://doi.org/10.1016/j. mpsur.2016.10.011

2. Sathya C, Alali AS, Wales PW, Scales DC, Karanicolas PJ, Burd RS, et al. Mortality among injured children treated at different trauma center types. JAMA Surg. 2015;150(9):874-81. https://doi.org/10.1001/jamasurg.2015.1121

3. Hedström EM, Svensson $O$, Bergström $U$, Michno $P$ Epidemiology of fractures in children and adolescents: Increased incidence over the past decade: A population-based study from Northern Sweden. Acta Orthop. 2010;81(1):148-53. https://doi. org/10.3109/17453671003628780

PMid:20175744

4. Landin LA. Fracture patterns in children. Analysis of 8, 682 fractures with special reference to incidence, etiology and secular changes in a Swedish urban population 1950-1979. Acta Orthop Scand Suppl. 1983;54 Suppl 202:3-109. https://doi. org/10.3109/17453678309155630

PMid:6574687

5. Wang H, Liu H, Wu J, Li C, Zhou Y, Liu J, et al. Age, gender, and etiology differences of sports-related fractures in children and adolescents: A retrospective observational study. Medicine (Baltimore). 2019 Jan;98(4):e13961. https://doi.org/10.1097/ MD.0000000000013961 PMid:30681556

6. Chaibi E, Zambelli PY, Merckaert S. Epidemiology of paediatric lower extremity fractures in a tertiary care center in Switzerland.
Eur J Trauma Emerg Surg. 2020. https://doi.org/10.1007/ s00068-020-01400-6

PMid:32462374

7. Liu H, Wang $H$, Shao B, Lu H, Zhang $S$, Ou L, et al. Epidemiological evaluation of traumatic lower limb fractures in children: Variation with age, gender, time, and etiology. Medicine (Baltimore). 2019;98(38):e17123. https://doi.org/10.1097/ MD.0000000000017123

PMid:31567950

8. Wijaya RK, Mustari MN. Evaluation of fracture on children in orthopaedic and traumatology division in Dr. Wahidin Sudirohusodo Central General Hospital Makassar January 2016-December 2017. Essence Med Sci. 2020;11(1):132. https://doi.org/10.15562/ism.v11i1.563

9. Nugraha HK, Adiantono A. Epidemiology of Fractures and Dislocations in Children Mode of Injury Road Traffic Accidents Falls below 1 Meter Falls Above 1 Meter Blunt Trauma; 2017. p. 1-5.

10. Engström Z, Wolf $O$, Hailer YD. Epidemiology of pediatric femur fractures in children: The Swedish fracture register. BMC Musculoskelet Disord. 2020;21(1):796. https://doi.org/10.1186/ s12891-020-03796-z

PMid:33261600

11. Sutphen SA, Mendoza JD, Mundy AC, Yang JG, Beebe AC, Samora WP $3^{\text {rd }}$, et al. Pediatric diaphyseal femur fractures: Submuscular plating compared with intramedullary nailing. Orthopedics. 2016;39(6):353-8. https://doi. org/10.3928/01477447-20160719-03

PMid:27459140

12. Hogue GD, Wilkins KE, Kim IS. Management of pediatric tibial shaft fractures. J Am Acad Orthop Surg. 2019;27(20):769-78. https://doi.org/10.5435/JAAOS-D-17-00819 PMid:30998564

13. Cruz AI Jr., Raducha JE, Swarup I, Schachne JM, Fabricant PD. Evidence-based update on the surgical treatment of pediatric tibial shaft fractures. Curr Opin Pediatr. 2019;31(1):92-102. https://doi.org/10.1097/MOP.0000000000000704 PMid:30461511

14. Messner J, Harwood P, Johnson L, Itte V, Bourke G, Foster P. Lower limb paediatric trauma with bone and soft tissue loss: Ortho-plastic management and outcome in a major trauma centre. Injury. 2020;51(7):1576-83. https://doi.org/10.1016/J. INJURY.2020.03.059

PMid:32444168 